\title{
IN VITRO- RAPID MULTIPLICATION OF AN IMPORTANT MEDICINAL PLANT TURNERA SUBULATA L.
}

\author{
Mythili Saravanan and P. Senthilkumar* \\ PG and Research Department of Biotechnology, Hindusthan College of Arts and Science, Coimbatore-641028 \\ *E.mail: drpsenthil13@gmail.com
}

\begin{abstract}
A highly stable, efficient and cost-effective, protocol for direct and indirect regeneration of a medicinal plant Turnera subulata. was established through the nodal culture using Murashige and Skoog's (MS) nutrient medium supplemented with various concentrations and combinations of growth hormones. The highest shoot proliferation (86\%) was observed on the MS medium enriched with BAP and IAA at 2.22 and $0.90 \mu \mathrm{m} / \mathrm{l}$ respectively. Effective shoot multiplication and elongation was observed on the same combination of growth regulators. The regenerated shoots was successfully rooted on MS medium supplemented with IBA alone at $2.46 \mu \mathrm{m} / \mathrm{l}$. After sequential hardening the survival rate of the plantlets was determined to be $93.8 \%$ under green house condition.
\end{abstract}

Keywords: Plant tissue culture, medicinal plant, Turnera subulata.

\section{INTRODUCTION}

Medicinal plants are the traditional sources for chemicals used as pharmaceutical products, food colors, fragrances and flavors. Plants high medicinal value are oldest friend for humans the backbone of folk medicine (Farnsworth, 1994). Almost $80 \%$ of the world population's primary health care need are fulfilled by plant based medicines. More than $25 \%$ of the drugs are plants based phyto compounds and $87 \%$ of human cancer therapy treated depend on plant based products (Shaikh et al., 2011).

Plant tissue culture plays a major role in the development ofthe commercial production of pathogen-free plants (Fay, 1992), and helps in the germplasm conservation of rare and endangered species (Campbell et al., 2003). The biotechnology applications like tissue culture plays an important role in the propagation of selected genotypes (Barrett, 2002). The plant raised through seeds, are highly heterozygous and shows greater variations in growth and yield when it is released as a commercial crop. Likewise, the majority of the plants are not responsive through vegetative propagation like cutting and grafting, which limits the multiplication of desired cultivars. Plants verities propagated through vegetative means contain plant pathogens like bacteria, fungi and viruses which may affect the appearanceandquality of selected items. In recent years, tissue culture has emerged as a promising technique to obtain genetically pure elite populations under in vitro conditions rather than having indifferent populations.

Turnera subulata belongs to the family Turneraceae which is one of the 28 angiosperm family showing heterostyly (Urban, 1883). Turnerais one of the most important genera of the family turneraceae which comprises more than 100 species, grouped into nine series (Barrett, 1998). Which are largely distributed in the tropical and subtropical region of Asia and Africa (Lorenzi, 2008). T. subulata is a polymorphic polyploid complex of perennial weeds commonly called 'Butter cup'. This variety is a dense, compact shrub that has dark green foliage and light yellow flower. Turnerais adopted as an ornamental plant, being used as the foundation, border, mass planting and ground cover (Gracioso et al., 2002). Turnera is also used as a tea for the treatment of disease related mainly to gastric dysfunction, research has produced data indicating that the plant extract has a significant antiulcerogenic effect (Kumar et al., 2005). The present study reports an efficient protocol through in-vitro culture by using nodal explant to increase their population to meet the needs.

\section{MATERIALS AND METHODS}

Study species were collected in and around Maruthamalai hills,Coimbatore. Healthy, young and disease free portion of the branches was selected and used as explants. Healthy nodal explants were selected and washed thoroughly under running tap water for $15 \mathrm{~min}$ to wash off the dust, dirt's and microbes present on the surface. The explants were cut $(1-2 \mathrm{~cm})$ separately and they were washed with a detergent solution (Tween 20) for $10 \mathrm{~min}$. After, they were thoroughly washed under running tap water until the traces of detergent solution were removed. Further steps of surface sterilization were carried out under aseptic conditions in the laminar air flow chamber. The shoots were then subjected to $70 \%$ ethanol treatment for 30 seconds and again washed with sterilized double distilled water at least three to 
four times, follows with mercuric chloride $\left(0.12 \% \mathrm{w} / \mathrm{v} \mathrm{HgCl}_{2}\right)$ solution for $3 \mathrm{~min}$ and rinsed four to five times with sterilized double distilled water. Sterilized explants were inoculated on MS medium for callus and shoot induction.

\subsection{Shoot initiation and multiplication}

For shoot induction, the nodal explants were cultured on MS medium supplemented with plant growth regulators like BAP and IAA in combinations for rapid shoot organogenesis. Twenty explants were used for each culture. The percent of explants responding for shoot formation were recorded after 35 days. In the subsequent subcultures, the multiple shoots from the nodal explants were carried out at the regular interval of 15-20 days.

\subsection{Rooting of in vitro produced shoots}

Shoots with 5-6 cm height was separated and individual shoots were transferred for rooting to MS medium containing different concentration of $\mathrm{Kn}$, IAA and IBA. The cultures were incubated under $16 \mathrm{~h}$ photoperiod for 15-20 days until the micro shoots developed the roots. Then the rooting frequency was measured.

\subsection{Acclimatization of plantlets}

The well-developed plantlets were removed from the culture bottles and washed with tap water to remove traces of agar and dipped in fungicide for a few minutes. Then the plantlets were planted on to net pot contains different type of potting media and survivability rate were determinate after 20 days of step-wise hardening processes. Hardened plants were transferred to a pot containing mixture of decomposed coir waste, garden soil and vermiculite (1:1:1 ratio). The pots were watered at two days interval under shade house condition. After 60 days, the frequency of survival was calculated.

\section{RESULTS AND DISCUSSION}

The morph genic response of nodal explants was observed on MS medium containing different

Table 2. Effect of different concentration of growth regulators on per cent of shoot multiplication, shoot number and shoot length after subculturing of in vitro derived shoots of Turnera subulata.

\begin{tabular}{ccccc}
\hline Growth Regulators $(\boldsymbol{\mu m} / \mathbf{l})$ & $\begin{array}{c}\text { Percent explants with } \\
\text { multiple shoots }\end{array}$ & $\begin{array}{c}\text { No. of shoots/ } \\
\text { explant }\end{array}$ & $\begin{array}{c}\text { Shoot } \\
\text { length (cm) }\end{array}$ \\
\hline BAP & IAA & $84.33 \pm 1.36$ & $4.33 \pm 1.03$ & $4.83 \pm 0.75$ \\
2.22 & 0.90 & $82.00 \pm 0.89$ & $2.83 \pm 0.75$ & $4.33 \pm 1.03$ \\
4.44 & 0.90 & $71.83 \pm 0.75$ & $2.16 \pm 0.75$ & $3.33 \pm 0.81$ \\
6.66 & 0.90 & $51.66 \pm 0.42$ & $1.66 \pm 0.33$ & $2.50 \pm 0.54$ \\
10.10 & 0.90 & $41.55 \pm 0.54$ & $3.66 \pm 0.81$ & $1.50 \pm 0.54$ \\
12.32 & 0.90 & $21.33 \pm 0.33$ & $2.33 \pm 0.51$ & $0.66 \pm 0.51$
\end{tabular}

concentration and combination of BAP and IAA. MS medium without growth regulators (control) induced no shoots. However, the multiplication rate, shoot number was higher in culture supplemented with growth regulators. The percentage of response varied with varying concentrations of growth regulators used. All the concentrations of BAP and IAA facilitated shoot bud differentiation. Swelling of dormant axillary bud took place within 8 days of inoculation and then differentiation into multiple shoots occurred after 35-40 days. The highest amount $(86.50 \%)$ of culture response was observed on MS medium supplemented with BAP and IAA at 2.22 and $0.90 \mu \mathrm{m} / \mathrm{l}$ respectively.

Table 1. Effect of different concentration of growth hormones added to the MS medium on shoot proliferation from nodel explants of Turnera subulata.

\begin{tabular}{ccc}
\hline $\begin{array}{c}\text { Growth Regulators } \\
(\boldsymbol{\mu m} / \mathbf{l})\end{array}$ & $\begin{array}{c}\text { \%of culture } \\
\text { response }\end{array}$ \\
\cline { 1 - 2 } BAP & IAA & $86.50 \pm 0.81$ \\
2.22 & 0.90 & $83.33 \pm 0.53$ \\
4.44 & 0.90 & $75.33 \pm 0.51$ \\
6.66 & 0.90 & $56.66 \pm 0.42$ \\
8.88 & 0.90 & $40.66 \pm 0.61$ \\
10.10 & 0.90 & $11.83 \pm 0.46$ \\
12.32 & 0.90 & $72.16 \pm 0.04$ \\
2.22 & 1.8 & $70.50 \pm 0.54$ \\
4.44 & 1.8 & $55.66 \pm 0.51$ \\
6.66 & 1.8 & $41.33 \pm 0.75$ \\
8.88 & 1.8 & $29.16 \pm 0.42$ \\
10.10 & 1.8 & $18.33 \pm 0.46$ \\
12.32 & 1.8 & $57.16 \pm 1.04$ \\
2.22 & 2.7 & $45.16 \pm 0.56$ \\
4.44 & 2.7 & $32.50 \pm 0.39$ \\
6.66 & 2.7 & $30.83 \pm 0.63$ \\
8.88 & 2.7 & $21.50 \pm 0.75$ \\
10.10 & 2.7 & $11.16 \pm 0.81$ \\
12.32 & 2.7 &
\end{tabular}




$\begin{array}{ccccc}2.22 & 1.8 & 62.00 \pm 0.63 & 3.33 \pm 0.51 & 3.00 \pm 0.63 \\ 4.44 & 1.8 & 61.66 \pm 0.51 & 3.00 \pm 0.63 & 2.66 \pm 0.81 \\ 6.66 & 1.8 & 51.50 \pm 0.54 & 3.16 \pm 0.30 & 2.33 \pm 0.51 \\ 8.88 & 1.8 & 41.50 \pm 0.54 & 2.66 \pm 1.03 & 2.00 \pm 0.81 \\ 10.10 & 1.8 & 21.33 \pm 0.51 & 2.33 \pm 0.33 & 1.50 \pm 0.54 \\ 12.32 & 1.8 & 11.16 \pm 0.40 & 2.00 \pm 0.44 & 0.91 \pm 0.04 \\ 2.22 & 2.7 & 47.83 \pm 0.75 & 2.00 \pm 0.57 & 2.83 \pm 0.75 \\ 4.44 & 2.7 & 41.66 \pm 0.81 & 2.00 \pm 0.63 & 2.50 \pm 0.54 \\ 6.66 & 2.7 & 31.66 \pm 0.49 & 1.50 \pm 0.54 & 1.83 \pm 0.75 \\ 8.88 & 2.7 & 28.33 \pm 0.33 & 1.33 \pm 0.51 & 1.50 \pm 0.54 \\ 10.10 & 2.7 & 21.33 \pm 0.51 & 1.00 \pm 0.63 & 1.51 \pm 0.03 \\ 12.32 & 2.7 & 17.00 \pm 0.57 & 0.85 \pm 0.71 & 0.83 \pm 0.75\end{array}$

Table 3. Effect of different concentration of growth regulators on rooting percentage, root number and root length after subculturing of shoots of Turnera subulata.

\begin{tabular}{|c|c|c|c|c|c|}
\hline \multicolumn{3}{|c|}{ Growth Regulators $(\mu \mathrm{m} / \mathrm{l})$} & \multirow{2}{*}{$\begin{array}{c}\text { \% Shoots } \\
\text { rooted }\end{array}$} & \multirow{2}{*}{$\begin{array}{l}\text { Number of } \\
\text { roots/shoot }\end{array}$} & \multirow{2}{*}{$\begin{array}{l}\text { Root length } \\
\quad \text { (cm) }\end{array}$} \\
\hline Kn & IAA & IBA & & & \\
\hline 5.35 & - & - & $70.33 \pm 0.33$ & $4.16 \pm 0.47$ & $3.85 \pm 0.69$ \\
\hline 10.74 & - & - & $63.83 \pm 0.04$ & $3.26 \pm 0.04$ & $3.66 \pm 0.51$ \\
\hline 15.05 & - & - & $51.66 \pm 0.30$ & $2.50 \pm 0.42$ & $2.85 \pm 0.69$ \\
\hline 20.40 & - & - & $24.16 \pm 0.63$ & $2.00 \pm 0.36$ & $3.00 \pm 0.63$ \\
\hline 25.75 & - & - & $50.16 \pm 0.42$ & $1.16 \pm 0.13$ & $1.16 \pm 0.75$ \\
\hline- & 2.86 & - & $46.53 \pm 0.75$ & $3.66 \pm 0.51$ & $2.85 \pm 0.75$ \\
\hline- & 5.72 & - & $34.82 \pm 1.03$ & $2.33 \pm 0.61$ & $2.00 \pm 0.63$ \\
\hline- & 8.58 & - & $23.62 \pm 0.81$ & $2.00 \pm 0.63$ & $2.00 \pm 0.63$ \\
\hline- & 11.44 & - & $21.43 \pm 0.03$ & $1.16 \pm 0.75$ & $1.00 \pm 0.89$ \\
\hline- & 14.30 & - & $13.16 \pm 0.63$ & $0.80 \pm 0.83$ & $0.85 \pm 0.69$ \\
\hline- & - & 2.46 & $87.34 \pm 0.52$ & $6.00 \pm .63$ & $5.66 \pm 0.81$ \\
\hline- & - & 4.92 & $84.83 \pm 0.81$ & $5.5 \pm 0.54$ & $4.83 \pm 0.75$ \\
\hline- & - & 6.38 & $44.66 \pm 0.75$ & $4.33 \pm 0.51$ & $3.26 \pm 0.04$ \\
\hline- & - & 8.84 & $24.16 \pm 0.32$ & $2.83 \pm 0.75$ & $2.42 \pm 053$ \\
\hline- & - & 10.30 & $10.16 \pm 0.63$ & $1.50 \pm 0.83$ & $1.53 \pm 0.02$ \\
\hline
\end{tabular}

Table 4. Effect of different composition of hardening medium on survivability of plantlets of Turnera subulata.

\begin{tabular}{cccc}
\hline Hardening medium composition(v/v) & $\begin{array}{c}\text { No. of plants } \\
\text { under hardening }\end{array}$ & $\begin{array}{c}\text { No. of plants } \\
\text { survived }\end{array}$ & $\begin{array}{c}\text { Percentage of } \\
\text { survivability }\end{array}$ \\
\hline Garden soil & 50 & 28 & 55.83 \\
Vermiculite & 50 & 30 & 60.83 \\
Decomposed coir waste & 50 & 40 & 80.50 \\
$\begin{array}{c}\text { Decomposed coir waste: garden soil: } \\
\text { vermiculite(1:1:1) }\end{array}$ & 50 & 47 & 93.83 \\
\hline
\end{tabular}

Follows that $83.33 \%$ of culture response was observed on MS medium containing BAP and IAA at 4.44 and $0.90 \mu \mathrm{m} / \mathrm{l}$ respectively. The remaining concentration BAP and IAA produced satisfactory results. Further, the increasing concentration of IAA in MS medium registered decreasing culture response. The result reported that, the nodal explant of the study species induced shoots at low concentration of growth regulators in the MS medium (Table 1). A similar kind of result was reported for the species, Bupleurum distichophyllum (Karuppusamy and Pullaih, 2007).

The in-vitro produced shoots was subcultured in MS medium enriched with different 
concentration of BAP and IAA for shoot multiplication. The highest (84.33\%) shoot multiplication was observed on the medium containing, BAP and IAA at 2.22 and $0.90 \mu \mathrm{m} / 1$ respectively. Whereas the highest number (4.33shoots) of shoot/ explant and high shoot length $(4.83 \mathrm{~cm})$ was observed in the MS medium enriched with BAP and IAA at 2.22 and $0.90 \mu \mathrm{m} / 1$ respectively (Table 2). However, the MS medium containing high concentration of growth regulator registered low percentage shoot multiplication. The varying response of explant for shoot multiplication depends on endogenus levels of growth hormones. The synergistic effect of auxin and cytokinin has been demonstrated in several medicinal plants viz., Buplerum fruticosum (Fraternale et al., 2002) and Rotula aquatic (Martin, 2003). In accordance with these reports, the present investigation also exemplifies the positive role of cytokinin in combination with auxin respects to induction of multiple shoots. In vitro produced shoots were transferred to MS medium supplemented with $\mathrm{Kn}$, IAA and IBA for root induction. Root formation from the basal cut end of the shoots was observed seven days after the transfer of shoots to the rooting medium without callus formation. The highest percentage (87.34\%) of rooting was achieved in MS medium containing IBA alone at $46 \mu \mathrm{M} / \mathrm{l}$. The highest number (5.66 roots) of roots per shoot and increased length $(81 \mathrm{~cm})$ of root were recorded after 20 days of culture (Table 3). Similar kind of results was reported in medicinal plants like Disporum leschenaultianum (Senthilkumar et al., 2009).The well-developed healthy in-vitro rooted plantlets were washed thoroughly and planted in different hardening substrate (Table 4). Among the four different substrate used, hardening medium composed of decomposed coir waste, garden soil and vermiculite in the ratio of $(1: 1: 1)$ was observed with higher survival percentage (93.83\%).

The simple, reproducible protocol raised in the present investigation could be used for mass multiplication of the plantlets of the T. subulata.

\section{REFERENCES}

Barrett, S.C.H. (1978) Heterostyly in a tropical weed: the reproductive biology of the Turnera ulmifolia Complex (Turneraceae). Can. J. Bot. 56, 1713-1725.

Barrett, S.C.H. (2002). The evolution of plant sexual diversity. Nat. Rev. Genet. 3, 274-284.
Campbell, M.M., Bruner, A.M., Jones, H.M. and Strauss, S.H. (2003) Forestry's fertilecresent: The application of biotechnology to forest tress. Plant Biotechnology Journal 1, 141-154.

Farnsworth N.R., (1994) Ethnopharmacology and drug discovery, Proceedings of Ciba foundation symposium, Wiley, Chinchester, 185, 42-59.

Fay, M.F. (1992) Conservation of rare and endangered plants using in vitro methods. In Vitro Cell. Dev. Biol. Plant. 28: 1-4.

Fraternale D., Giamperi, L., Ricci, D.X and Rocchi, M.B.L. (2002). Micropropagation of Bupleurum fruticosum: the effect of tricontand, Plant cell tissue orsanclub. 69: 135-140.

Gracioso J. L., Vilégas W., Hiruma-Lima C. A., Brito A. R. M. S. (2002). Effect of tea from Turnera ulmifolia $\mathrm{L}$. on mouse gastric mucosa support the Turneraceae as a new source of antiulcerogenic drugs.- Biological and Pharmaceutical Bulletin,25: 487-491.

Karrupusamy, S. and Pullaiah, T. (20007). In vitro shoot multiplication of Buplerum distichiphyllum Wight- A native medicinal plant of Southern India, Plant Tissue Culture. and Biotech, 17(2): 115-124.

Kumar, S., Taneja, R. and Sharma. A. (2005). The genus Turnera: a review update. Pharmaceutical Biology 43: 383-391.

Lorenzi H. (2008). Plantas ornamentais no Brasil: arbustivas, herbáceas e trepadeiras- Nova Odessa, São Paulo: Instituto Plantarum.

Martin, K.P (2003). Rapid in-vitro multiplication and ex-vivo rooting of Rotula aquatica Lour. A rare rhoephytic woody medicinal plant. Plant cell Rep., 21, 415-420.

Senthilkumar, P., Paulsamy, S., Sivashanmugam, M. and Mallikadevi, T. (2009). In-vitro multiplication of Disporum leschenaultianum D. Don. A reare and threatened medicinal plant. International Journ of Biotechnology and Biochemistry, 5 (1): 35-41.

Shaikh J., Uddin I., Darren Grice and Evelin Tiralongo, (2011). Cytotoxic effects of Bangladesh Medicinal Plant Extracts, Evidence-Based Complementary and Alternative Medicine, 21, 7.

Urban, I. (1883). Monographic der Familie der Turneraceae. Jahrb. Ko" nigl. Bot. Garten Museum 2, 1-155. 